\title{
Tuning surface properties of amino-functionalized silica for metal nanoparticle loading: the vital role of an annealing process
}

\author{
Yuchen Pei, Chaoxian Xiao, Tian-Wei Goh, Qianhui Zhang, Shannon Goes, Weijun Sun, Wenyu Huang* \\ Department of Chemistry, Iowa State University \\ Ames Laboratory, US Department of Energy, Ames, IA 50011, United States. \\ *Corresponding author. E-mail: whuang@iastate.edu
}

\begin{abstract}
Metal nanoparticles (NPs) loaded on oxides have been widely used as multifunctional nanomaterials in various fields such as optical imaging, sensors, and heterogeneous catalysis. However, the deposition of metal NPs on oxide supports with high efficiency and homogeneous dispersion still remains elusive, especially when silica is used as the support. Amino-functionalization of silica can improve loading efficiency, but metal NPs often aggregate on the surface. Herein, we report that a facial annealing of aminofunctionalized silica can significantly improve the dispersion and enhance the loading efficiency of various metal NPs, such as Pt, Rh, and Ru, on the silica surface. A series of characterization techniques, such as diffuse reflectance infrared Fourier transform spectroscopy (DRIFT), Zeta potential analysis, UV-vis spectroscopy, thermogravimetric analysis coupled with infrared analysis (TGA-IR), and nitrogen adsorption, were employed to study the changes of surface properties of the amino-functionalized silica before and after annealing. We found that the annealed amino-functionalized silica surface has more cross-linked silanol groups and relatively lesser amount of amino groups, and less positively charges, which could be the key to the uniform deposition of metal NPs during the loading process. These results could contribute to the preparation of metal/oxide hybrid NPs for the applications that require uniform dispersion.
\end{abstract}

\section{Keyword}

Amino-functionalized silica, Annealing, Dispersion, Monodisperse, Supports, Uniform

\section{Introduction}

Hybrid NPs, endowed with two or more unique properties, have been the focus of growing attention as advanced nanoarchitectures in a wide spectrum of applications, such as optical and magnetic imaging, drug delivery, energy harvesting, and heterogeneous catalysis.[1-8] Of specific interest are inorganic hybrid NPs that metal NPs ( $\mathrm{Au}, \mathrm{Ru}, \mathrm{Pt}$, Pd etc.) decorated on well-designed metal oxides $\left(\mathrm{SiO}_{2}, \mathrm{Al}_{2} \mathrm{O}_{3}\right.$ and $\left.\mathrm{Fe}_{3} \mathrm{O}_{4}\right)$. [9-16] For example, $\mathrm{Au} / \mathrm{SiO}_{2}$ with tunable sizes is effectively utilized in surface-enhanced Raman spectroscopy (SERS) and surface plasmon resonance (SPR).[17] Replacing the $\mathrm{SiO}_{2}$ support with magnetic $\mathrm{Fe}_{3} \mathrm{O}_{4}$, the obtained hybrid $\mathrm{Au} / \mathrm{Fe}_{3} \mathrm{O}_{4} \mathrm{NPs}$ have been considered as promising candidates for in-vivo diagnostic tests that include both optical detection and targeting capabilities under an external magnetic field.[18, 19] Using Rh, $\mathrm{Pt}$, and Pd NPs, the design of versatile supported heterogeneous oxide-supported metal hybrid NPs can also be achieved, such as $\mathrm{Rh} / \mathrm{SiO}_{2}, \mathrm{Pd} / \mathrm{Al}_{2} \mathrm{O}_{3}$ and $\mathrm{Pt} / \mathrm{CeO}_{2}$.[20-22] The assembly of metal NPs on oxides possesses exceptional advantages ranging from the size control of metal NPs, enhanced thermal stabilities provided by oxide supports, and the utilization of metal-oxide interactions. These evince the metal/oxide hybrid NPs as multifunctional catalysts for a number of reactions.

The dispersion homogeneity and size uniformity of these hybrid NPs are highly desirable, due to the size and shape-dependent properties in practical applications. For catalytic purposes, the aggregation of NPs would significantly deactivate catalysts, due to the decreased surface area. Well-dispersed and separated metal NPs on oxide supports are thus beneficial to relieve the aggregation tendency of NPs during thermal pretreatment and harsh catalytic reaction conditions.[5] Monodispersity and size homogeniety of hybrid NPs are also regarded as important criteria in the fabrication of efficient light harvesting materials and solar cell films.[23] 
Surface smoothness, interparticle spacing and uniformity of the self-assembled NPs are also highly demanded for high quality optical detection and magnetic resonance imaging.[24]

Several conventional strategies have been studied to obtain various metal/oxide hybrid NPs[25-29]: i) growth of metal components on oxides or reversed approach, such as reduction of metal ions on preformed oxides NPs[30-37], decomposition of one metal precursor on other preformed metal NPs followed by oxidation[38], and chemical-triggered phase segregation of alloy NPs[39]; and ii) direct deposition of preformed metal NPs on oxides via colloidal method[9, 11, 40]. Strategy i) is challenging to accomplish the uniform growth of metal NPs on other surfaces. Strategy ii) provides a more advantageous platform to prepare metal/oxide hybrid NPs with precise controls in size and geometry by isolating the synthesis of metal NPs and oxide substrates in advance of the colloidal deposition. Among the direct deposition, charged metal NPs can be well dispersed on various substrates due to the electrostatic repulsion between metal NPs.[9] Hydrophobic/hydrophilic interactions also play important roles in instances that involve loading ligandprotected neutral metal NPs onto substrates.[15] Nevertheless, the direct assembly of metal NPs on bare oxides with uniform dispersion and high loading efficiency is still challenging due to the complicated surface compatibility of metal/oxide interfaces derived from diverse synthetic methods. Chemical functionalization of the oxides is an alternative strategy to enhance metal NP-oxide interactions utilizing the chemical bonding. Amino-, thiol- and carboxylic-terminated alkyl groups are commonly functionalized on the surface of silica to anchor various ligand-capped precious metal NPs through strong coordinating interactions, such as $\mathrm{Au}, \mathrm{Pt}, \mathrm{Rh}$ and Pd.[41] However, the general mechanism of assembly remains unsolved leading to the empirical endeavors in the fabrication of metal/oxide hybrid NPs.

Recent studies have revealed that the pretreatment steps on oxide substrates, such as heating and drying, can tune the surface characteristics[42] and thus likely improve the uniformity of the coating material on such substrate. For example, a mild thermal treatment of $\mathrm{SiO}_{2}$ was found to be advantageous to obtain conformal $\mathrm{CeO}_{2}$ coatings in the synthesis of $\mathrm{SiO}_{2} @ \mathrm{CeO}_{2} \mathrm{NPs}$.[43] In this article, we have used amino-functionalized silica spheres $\left(\mathrm{NH}_{2}-\mathrm{SiO}_{2}\right)$ as a model system to study the loading of metal NPs on them. We demonstrate herein that the annealing process performed on $\mathrm{NH}_{2}-\mathrm{SiO}_{2}$ can largely improve both the dispersion and loading efficiency of diverse precious metal NPs. We explored the surface variance of $\mathrm{NH}_{2}-\mathrm{SiO}_{2}$ pertaining to this annealing process, zeroing in on the most important factors that affect the loading of metal NPs. This annealing process can be easily executed, thus broadening its technical applications for the efficient manufacture of various metal/oxide nanostructures.

\section{Experimental section}

\subsection{Chemicals}

Methanol, ethanol, isopropanol, ammonium hydroxide (28\%) and ethylene glycol (EG), cyclohexane were purchased from Fisher Scientific. 3-aminopropyltriethoxysilane (APTS, 99\%), and $\mathrm{RhCl}_{3} \cdot \mathrm{xH}_{2} \mathrm{O}$ were obtained from Alfa Aesar. $\mathrm{K}_{2} \mathrm{PtCl}_{4}$ and $\mathrm{K}_{2} \mathrm{PdCl}_{4}$ were obtained from Acros Organics. $\mathrm{RuCl}_{3} \cdot \mathrm{xH}_{2} \mathrm{O}$, tetraethyl orthosilicate (TEOS, 98\%), L-arginine, polyvinylpyrrolidone (PVP, K30), myristyltrimethylammonium bromide $\left(\mathrm{C}_{14} \mathrm{TAB}\right)$ and hexadecyltrimethylammonium bromide $\left(\mathrm{C}_{16} \mathrm{TAB}\right)$ were obtained from SigmaAldrich.

2.2 The synthesis of $200 \mathrm{~nm} \mathrm{SiO}_{2}$ spheres with uniform particle size (deviation $<5 \%$ )

$200 \mathrm{~nm} \mathrm{SiO}_{2}$ spheres were synthesized by a four-step seeded growth approach.[44]

$24 \mathbf{~ n m ~ S i O} 2$ seeds: $18.2 \mathrm{mg} \mathrm{L}$-arginine and $13.9 \mathrm{~mL}$ of ultrapure water were mixed thoroughly. Then $0.9 \mathrm{~mL}$ of cyclohexane was added gently to the water-arginine solution without disturbing the two-layer solution. The solution was heated to $60.0 \pm 0.2{ }^{\circ} \mathrm{C}$ for $30 \mathrm{~min}$ at $300 \mathrm{rpm} .1 .10 \mathrm{~mL}$ of TEOS was added to the mixture. The reaction was kept for $20 \mathrm{hrs}$ at $60{ }^{\circ} \mathrm{C}$. After reaction, the bottom layer was taken out and kept in the refrigerator (Sample A).

$45 \mathrm{~nm} \mathrm{SiO}$ seeds: $4 \mathrm{~mL}$ of the $24 \mathrm{~nm}$ seeds (Sample A) was taken and diluted with $14.4 \mathrm{~mL}$ ultrapure water after which $2 \mathrm{~mL}$ cyclohexane was added. The mixture was brought to $60{ }^{\circ} \mathrm{C}$ for $30 \mathrm{~min}$ at $300 \mathrm{rpm}$. Then $1.408 \mathrm{~mL}$ TEOS was added to the top layer immediately, and the mixture was kept at $60^{\circ} \mathrm{C}$ for $30 \mathrm{hrs}$. After reaction, the bottom layer was taken out and kept in refrigerator (Sample B).

$82 \mathrm{~nm} \mathrm{SiO}$ seeds using Stöber method: $1 \mathrm{~mL}$ of the $45 \mathrm{~nm}$ seeds (Sample B) was taken and diluted with $2.6 \mathrm{~mL}$ deionized water and $18 \mathrm{~mL}$ ethanol. Subsequently, $1.7 \mathrm{~mL} \mathrm{NH}_{3} \cdot \mathrm{H}_{2} \mathrm{O}(\sim 28 \%)$ was added. The 
solution was mixed at $\sim 500 \mathrm{rpm}$ for $1 \mathrm{hr}$ at room temperature. Total $0.8 \mathrm{~mL}$ TEOS was added to the solution dropwise, three times at intervals of 30 mins. The solution was stirred for 6 hrs and later kept in the refrigerator (Sample C)

$200 \mathrm{~nm} \mathrm{SiO}$ spheres using Stöber method: $1 \mathrm{~mL}$ of the $82 \mathrm{~nm}$ seeds (Sample C) was taken and diluted with $2.6 \mathrm{~mL}$ deionized water and $18 \mathrm{~mL}$ ethanol. $1.7 \mathrm{~mL} \mathrm{NH}_{3} \cdot \mathrm{H}_{2} \mathrm{O}(\sim 28 \%)$ was added. The solution was mixed at $\sim 500 \mathrm{rpm}$ for $1 \mathrm{hr}$. A total volume of $0.44 \mathrm{~mL}$ TEOS was added to the solution dropwise twice at intervals of 30 mins. After $6 \mathrm{hrs,} 200 \mathrm{~nm} \mathrm{SiO}$ spheres (Sample D) were obtained and kept in the refrigerator for further use. This step could be easily scaled up. In our lab, $>10 \mathrm{~g}$ silica spheres could be obtained in one batch. The size deviation is typically within $\pm 10 \mathrm{~nm}$.

The purification of $\mathrm{SiO}_{2}$ spheres was conducted by washing them 5 times with an ethanol/water solution $(50 / 50 \mathrm{v} / \mathrm{v})$. The purified $\mathrm{SiO}_{2}$ spheres were stored in ethanol.

2.3 The synthesis of $5 \mathrm{~nm} \mathrm{Pt}, 4 \mathrm{~nm} \mathrm{Rh}$, and $1.8 \mathrm{~nm} \mathrm{Ru} \mathrm{NPs}$

All metal NPs were synthesized according to previously reported literature with modifications.[45]

$5 \mathrm{~nm}$ Pt NPs: $41.5 \mathrm{mg} \mathrm{K}_{2} \mathrm{PtCl}_{4}, 505 \mathrm{mg} \mathrm{C} 14 \mathrm{TAB}$ and $222 \mathrm{mg}$ PVP (K30) were mixed in $20 \mathrm{~mL}$ EG with sonication. Under argon protection, the mixed solution was heated to $140{ }^{\circ} \mathrm{C}$ for $2 \mathrm{hrs}$. After reaction, Pt NPs were precipitated by adding excessive acetone (acetone:EG $=9: 1$ ). The precipitate was further washed 5 times with an ethanol/hexane mixture (1/4 v/v). Purified $5 \mathrm{~nm}$ Pt NPs were dispersed in $20 \mathrm{~mL}$ ethanol.

$4 \mathbf{n m}$ Rh NPs and $1.8 \mathrm{~nm}$ Ru NPs: The synthetic conditions and purification procedure are the same as 5 $\mathrm{nm}$ Pt NPs except for using $20.7 \mathrm{mg} \mathrm{RhCl}_{3} \cdot \mathrm{xH}_{2} \mathrm{O}$ and $20.7 \mathrm{mg} \mathrm{RuCl}_{3} \cdot \mathrm{xH}_{2} \mathrm{O}$ respectively as starting materials.

2.4 The synthesis of $\mathrm{NH}_{2}-\mathrm{SiO}_{2}[5,40]$

$1.0 \mathrm{~g} \mathrm{SiO}_{2}$ spheres $(1.0 \mathrm{~g})$ were centrifuged from the original ethanol solution and re-dispersed in $175 \mathrm{~mL}$ isopropanol. $200 \mu \mathrm{L}$ APTS was dissolved in $25 \mathrm{~mL}$ isopropanol and mixed with the above $\mathrm{SiO}_{2}$-isopropanol solution. A round-bottom flask containing the mixed solution was heated to $80{ }^{\circ} \mathrm{C}$. The reaction was stopped after $2 \mathrm{hrs}$. $\mathrm{NH}_{2}-\mathrm{SiO}_{2}$ spheres were separated, washed with ethanol 3 times and stored in $20 \mathrm{~mL}$ ethanol.

2.5 The annealing process of $\mathrm{NH}_{2}-\mathrm{SiO}_{2}$

As-synthesized $\mathrm{NH}_{2}-\mathrm{SiO}_{2}$ spheres were taken out from their ethanol solution and dried in vacuum at room temperature. The dried solids were annealed in an oven in air at $100{ }^{\circ} \mathrm{C}$ for $5 \mathrm{hrs}$, then cooled down to room temperature naturally.

2.6 The preparation of metal NPs (M) loaded on $\mathrm{NH}_{2}-\mathrm{SiO}_{2}\left(\mathrm{M} / \mathrm{NH}_{2}-\mathrm{SiO}_{2}\right)$

Typically, $200 \mathrm{mg} \mathrm{NH}_{2}-\mathrm{SiO}_{2}$ (fresh or annealed) spheres were taken out and dispersed in $60 \mathrm{~mL}$ ethanol. The appropriate amount of the metal NPs solution was taken out according to the desired metal loading and diluted to a final volume of $110 \mathrm{~mL}$ with ethanol. The $110 \mathrm{~mL}$ diluted metal NPs solution was added to 60 $\mathrm{mL} \mathrm{NH} \mathrm{N}_{2}-\mathrm{SiO}_{2}$ solution dropwise with vigorous magnetic stirring. After addition, the resulting $\mathrm{M} / \mathrm{NH}_{2}-\mathrm{SiO}_{2}$ solution was further sonicated for $30 \mathrm{~min}$. After separation, the $\mathrm{M} / \mathrm{NH}_{2}-\mathrm{SiO}_{2}$ precipitate was washed with ethanol 5 times and stored in ethanol.

\subsection{Characterization details}

The morphology of $\mathrm{NH}_{2}-\mathrm{SiO}_{2}$ spheres and $\mathrm{M} / \mathrm{NH}_{2}-\mathrm{SiO}_{2}$ were investigated using transmission electron microscopy (TEM) recorded on a Tecnai G2 F20 electron microscope operated at $200 \mathrm{kV}$. Diffuse reflectance infrared Fourier transform spectroscopy (DRIFTS) measurements were performed using an Agilent Cary 670 FTIR equipped with a linearized MCT detector, a Harrick diffuse reflectance accessory, and a Praying Mantis high-temperature reaction chamber. Zeta potential analysis was conducted in neutral ethanol solvent under a Malvern Zetasizer Nano ZS90 with MPT-2 autotitrator. The amount of amine sites on modified silica spheres was determined by titration: $150 \mathrm{mg}$ of $\mathrm{NH}_{2}-\mathrm{SiO}_{2}$ was dispersed in $5.0 \mathrm{~g}$ ultrapure water with sonication. The solution was neutralized with $0.1 \mathrm{M} \mathrm{NaOH}$ solution first, and then back titrated with $0.1 \mathrm{M} \mathrm{HCl}$ solution in the presence of bromothymol blue indicator. The surface area measurements were performed with $\mathrm{N}_{2}$ adsorption/desorption isotherms at $-196{ }^{\circ} \mathrm{C}$ on a Micromeritics $3 \mathrm{Flex}$ instrument. Before the analysis, the samples were evacuated under vacuum $\left(\sim 5-10^{-5}\right.$ Torr $)$ for $12 \mathrm{hrs}$ at room 
temperature. The diffuse reflectance UV-Vis spectra and transmission UV-Vis spectra were acquired using StellaNet Black-Comet C-SR-100 spectrometer and Varian Cary 50 Bio UV-Visible spectrophotometer respectively. The loading amounts of metal $\mathrm{NPs}$ on $\mathrm{NH}_{2}-\mathrm{SiO}_{2}$ were determined using inductively coupled plasma mass spectrometry (ICP-MS; Thermo Scientific XSeries II). TGA-IR experiments were performed on Netzsch DSC/TGA-MS/IR in $\mathrm{O}_{2} / \mathrm{N}_{2}$ flow $(10 / 40 \mathrm{~mL} / \mathrm{min})$.

\section{Results and discussion}

We utilized the general colloidal method to load metal $\mathrm{NPs}$ on $\mathrm{NH}_{2}-\mathrm{SiO}_{2}$ spheres. Uniform metal NPs and monodisperse $200 \mathrm{~nm} \mathrm{NH}-\mathrm{SiO}_{2}$ spheres were synthesized following reported literatures[44, 45] and diluted to certain volumes before the loading process. The homogeneous colloidal solution of metal NPs was added dropwise into the pre-diluted ethanol solution of $\mathrm{NH}_{2}-\mathrm{SiO}_{2}$ under vigorous stirring. The annealing process utilized for $\mathrm{NH}_{2}-\mathrm{SiO}_{2}$ was found to be essential to obtain well-dispersed metal NP loadings. After vacuum drying them at room temperature, the as-made $\mathrm{NH}_{2}-\mathrm{SiO}_{2}$ powders were annealed at $100{ }^{\circ} \mathrm{C}$ in air for $5 \mathrm{hrs}$, denoted as "annealed $\mathrm{NH}_{2}-\mathrm{SiO}_{2}$ ". We also loaded metal $\mathrm{NPs}$ on fresh $\mathrm{NH}_{2}-\mathrm{SiO}_{2}$ spheres without the annealing process as experimental controls. Other synthetic conditions related to the dispersion of metal NPs loadings were carefully controlled to be constants, such as dropping rate, stirring rate, and the total volume of metal NPs and $\mathrm{NH}_{2}-\mathrm{SiO}_{2}$ solutions. We used three precious metal NPs including $\mathrm{Pt}, \mathrm{Rh}$ and $\mathrm{Ru}$ to illustrate the dispersion of metal NPs on $\mathrm{NH}_{2}-\mathrm{SiO}_{2}$. These samples are denoted as $5 \mathrm{~nm} \mathrm{Pt} / \mathrm{NH}_{2}-\mathrm{SiO}_{2}, 4 \mathrm{~nm}$ $\mathrm{Rh} / \mathrm{NH}_{2}-\mathrm{SiO}_{2}$ and $1.8 \mathrm{~nm} \mathrm{Ru} / \mathrm{NH}_{2}-\mathrm{SiO}_{2}$. With $5 \mathrm{wt} \%$ target loadings of $\mathrm{Pt}, \mathrm{Rh}$ and $\mathrm{Ru} \mathrm{NPs}$, the actual loading amounts of metal to $\mathrm{NH}_{2}-\mathrm{SiO}_{2}$ were determined by ICP-MS.

TEM images of $5 \mathrm{~nm} \mathrm{Pt}, 4 \mathrm{~nm} \mathrm{Rh}$ and $1.8 \mathrm{~nm} \mathrm{Ru}$ NPs on fresh and annealed $\mathrm{NH}_{2}-\mathrm{SiO}_{2}$ are shown in Figure 1. The dispersion of metal NPs on annealed $\mathrm{NH}_{2}-\mathrm{SiO}_{2}$ was significantly improved compared to fresh $\mathrm{NH}_{2}$ $\mathrm{SiO}_{2}$. For $5 \mathrm{~nm} \mathrm{Pt}, 4 \mathrm{~nm} \mathrm{Rh}$ and $1.8 \mathrm{~nm} \mathrm{Ru} \mathrm{NPs}$, it is clearly seen that many domains of NP aggregations were observed when loaded on fresh $\mathrm{NH}_{2}-\mathrm{SiO}_{2}$. These domains comprise of several NPs piled on each other and lead to some $\mathrm{NH}_{2}-\mathrm{SiO}_{2}$ agglomerations. Even though some separated NPs were found on the surface of fresh $\mathrm{NH}_{2}-\mathrm{SiO}_{2}$, they were not distributed evenly. After treating the fresh $\mathrm{NH}_{2}-\mathrm{SiO}_{2}$ with the annealing process, all metal NPs can be loaded uniformly and clearly appear to be separated on the annealed $\mathrm{NH}_{2}-\mathrm{SiO}_{2}$ surface. It is evident that the annealing process is crucial in achieving the exceptional uniform dispersion of metal NPs on the $\mathrm{NH}_{2}-\mathrm{SiO}_{2}$ surface.

To investigate the key role of the annealing process in the dispersion of metal loadings, we used nitrogen adsorption, acid-base titration, TGA-IR, DRIFT and Zeta potential analysis to study the surface characteristics of both fresh and annealed $\mathrm{NH}_{2}-\mathrm{SiO}_{2}$. The surface area of $\mathrm{NH}_{2}-\mathrm{SiO}_{2}$ was measured with $\mathrm{N}_{2}$ adsorption performed at $-196^{\circ} \mathrm{C}$. As shown in Figure 2, the isotherms of both fresh and annealed $\mathrm{NH}_{2}-\mathrm{SiO}_{2}$ samples show type II characteristics. The detailed results are summarized in Table 1. BET surface areas of fresh and annealed $\mathrm{NH}_{2}-\mathrm{SiO}_{2}$ were determined to be 14.0 and $14.4 \mathrm{~m}^{2} \cdot \mathrm{g}^{-}{ }^{1}$, respectively. For fresh and annealed samples, the respective micropore volume is 0.0016 and $0.0019 \mathrm{~m}^{3} \cdot \mathrm{g}^{1}$. The BET surface areas are intrinsically the same to the theoretical value $\left(14.4 \mathrm{~m}^{2} \cdot \mathrm{g}^{-}\right)$, obtained using the following equation:[46]

$$
A=\frac{6000}{\rho d}
$$

Where $\rho$ is the density of amorphous silica $\left(2.08 \mathrm{~g} \cdot \mathrm{cm}^{3}\right)$ and $\boldsymbol{d}$ is the diameter of the silica spheres $(200 \mathrm{~nm})$. These results suggest that the fresh and annealed $\mathrm{NH}_{2}-\mathrm{SiO}_{2}$ spheres are non-porous. However, we should point out that we only activated $\mathrm{NH}_{2}-\mathrm{SiO}_{2}$ under vacuum at room temperature for $12 \mathrm{hrs}$, which could still leave micropores (if any) filled with solvent molecules and thus cannot be detected by $\mathrm{N}_{2}$ physisorption.

Amino groups attached to $\mathrm{NH}_{2}-\mathrm{SiO}_{2}$ spheres are vital to bind metal NPs. The amount of amino groups was determined by acid-base titration, as shown in Table 2 . The number of amino sites per square nanometer was measured to be $12.1 \pm 0.6$ for the fresh $\mathrm{NH}_{2}-\mathrm{SiO}_{2}$. This number is higher than the typical concentration of surface silanol groups on silica surface $\left(3-7 \mathrm{ea} \cdot \mathrm{nm}^{-2}\right)$.[47] However, it is known that preparation and pretreatment methods could lead to such changes,[48] and it possibly implies that dangling oligomers of amino-polysiloxanes could present during the amino functionalization of silica spheres. Also, we noticed that 
measured BET surface areas of $\mathrm{NH}_{2}-\mathrm{SiO}_{2}$ sphere were likely lower than the actual surface areas due to the insufficient degas process performed at room temperature. Using the underestimated silica surface area in amino group density calculation could lead to a higher than expected value. After the annealing process, the number of amino groups dramatically dropped to $0.29 \pm 0.05 \mathrm{ea} \cdot \mathrm{nm}^{-2}$. We speculate that the reduction of accessible amino sites on the surface could be due to the chemical decomposition or the cleavage of the oligomers of amino-polysiloxanes during the annealing process. This was confirmed using the TGA-IR technique and is discussed later.
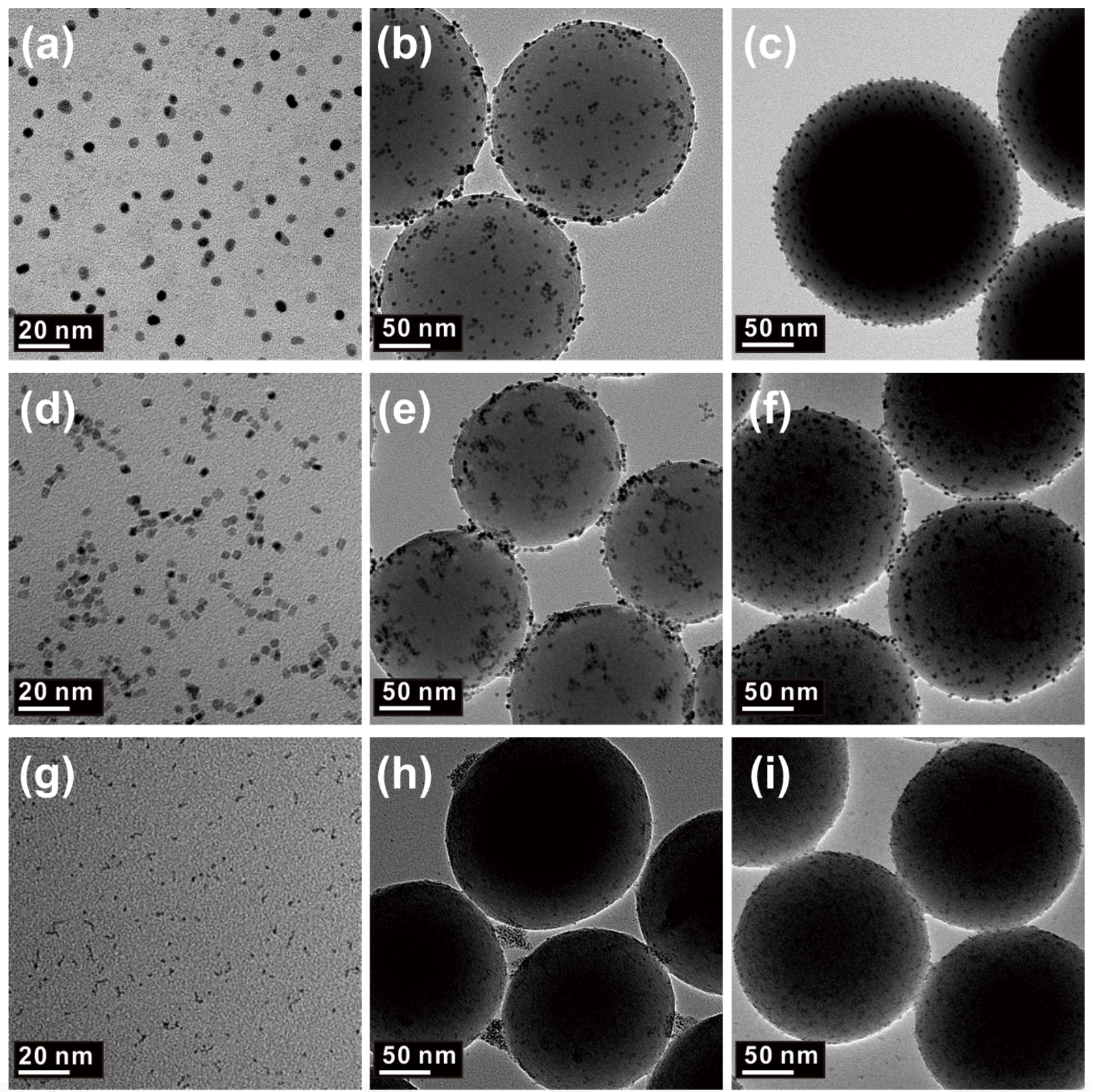

Figure 1. TEM images of (a) $5 \mathrm{~nm} \mathrm{Pt} \mathrm{NPs;} \mathrm{(b)} 5 \mathrm{~nm} \mathrm{Pt} /$ fresh $\mathrm{NH}_{2}-\mathrm{SiO}_{2}$; (c) $5 \mathrm{~nm} \mathrm{Pt} /$ annealed $\mathrm{NH}_{2}-\mathrm{SiO}_{2}$; (d) $4 \mathrm{~nm} \mathrm{Rh} \mathrm{NPs}$; (e) $4 \mathrm{~nm} \mathrm{Rh} /$ fresh $\mathrm{NH}_{2}-\mathrm{SiO}_{2}$; (f) $4 \mathrm{~nm} \mathrm{Rh/annealed} \mathrm{NH}_{2}-\mathrm{SiO}_{2}$; (g) $1.8 \mathrm{~nm} \mathrm{Ru} \mathrm{NPs}$; (h) $1.8 \mathrm{~nm}$ $\mathrm{Ru} /$ fresh $\mathrm{NH}_{2}-\mathrm{SiO}_{2}$; (i) $1.8 \mathrm{~nm} \mathrm{Ru} /$ annealed $\mathrm{NH}_{2}-\mathrm{SiO}_{2}$. 
Table 1. Nitrogen adsorption of amino-functionalized silica spheres ${ }^{\text {a }}$

\begin{tabular}{lcccccc}
\hline Sample & $\begin{array}{l}\text { BET } \\
\text { surface area } \\
\left(\mathrm{m}^{2} \cdot \mathrm{g}^{1}\right)\end{array}$ & $\begin{array}{l}\text { Langmuir } \\
\text { Surface area } \\
\left(\mathrm{m}^{2} \cdot \mathrm{g}^{1}\right)\end{array}$ & $\begin{array}{l}\text { Microporous } \\
\text { surface area } \\
\left(\mathrm{m}^{2} \cdot \mathrm{g}^{1}\right)^{\mathrm{b}}\end{array}$ & $\begin{array}{l}\text { External } \\
\text { surface area } \\
\left(\mathrm{m}^{2} \cdot \mathrm{g}^{1}\right)^{\mathrm{b}}\end{array}$ & $\begin{array}{l}\text { Micropore } \\
\text { volume } \\
\left(\mathrm{m}^{3} \cdot \mathrm{g}^{-1}\right)^{\mathrm{b}}\end{array}$ & $\begin{array}{l}\text { Calculated } \\
\text { surface area } \\
\left(\mathrm{m}^{2} \cdot \mathrm{g}^{1}\right)^{\mathrm{c}}\end{array}$ \\
\hline $\begin{array}{l}\text { Fresh } \\
\mathrm{NH}_{2}-\mathrm{SiO}_{2}\end{array}$ & 14.0 & 17.1 & 3.5 & 10.4 & 0.0016 & 14.4 \\
$\mathrm{Annealed}^{\mathrm{N} \mathrm{NH}_{2}-\mathrm{SiO}_{2}}$ & 14.4 & 17.1 & 3.5 & 10.9 & 0.0019 & 14.4 \\
\hline
\end{tabular}

${ }^{a}$ Approximately $500 \mathrm{mg} \mathrm{SiO}_{2}$ was used in each experiment. ${ }^{\mathrm{b}}$ Obtained from t-plot analysis between the range 5.1-7.8 $\AA$, which is a straight line. ${ }^{\mathrm{c}}$ A diameter of $200 \mathrm{~nm}$ and a density of $2.08 \mathrm{~g} \cdot \mathrm{cm}^{-1}$ was assumed for the silica spheres.

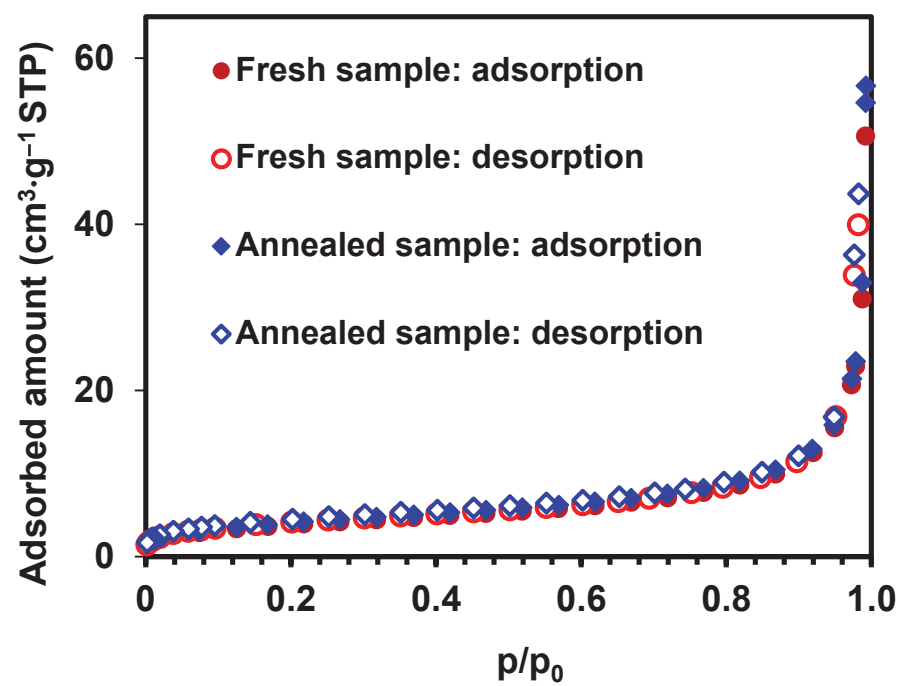

Figure 2. The $\mathrm{N}_{2}$ adsorption-desorption isotherms of fresh $\mathrm{NH}_{2}-\mathrm{SiO}_{2}$ and annealed $\mathrm{NH}_{2}-\mathrm{SiO}_{2}$.

Table 2. Determination of amino groups on silica spheres with acid-base titration ${ }^{\text {a }}$

\begin{tabular}{lcc}
\hline Sample & $\begin{array}{c}\text { Amount of Amino groups } \\
\left(\mathrm{mol} \cdot \mathrm{g}^{-1}\right)\end{array}$ & $\begin{array}{c}\text { Concentration of amino groups } \\
\left(\mathrm{ea} \cdot \mathrm{nm}^{2}\right)^{\mathrm{b}}\end{array}$ \\
\hline Fresh $\mathrm{NH}_{2}-\mathrm{SiO}_{2}$ & $2.8 \pm 0.1 \times 10^{-4}$ & $12.1 \pm 0.6$ \\
Annealed $\mathrm{NH}_{2}-\mathrm{SiO}_{2}$ & $7.0 \pm 1.1 \times 10^{-6}$ & $0.29 \pm 0.05$ \\
\hline
\end{tabular}

${ }^{a}$ Approximately $150 \mathrm{mg} \mathrm{SiO}{ }_{2}$ sample was used in each experiment. ${ }^{b}$ Measured BET surface area was used in the calculations.

The quantity difference of surface amino groups on fresh $\mathrm{NH}_{2}-\mathrm{SiO}_{2}$ and annealed $\mathrm{NH}_{2}-\mathrm{SiO}_{2}$ were further determined by spectrometric methods using Rhodamine $\mathrm{B}$ as the probe molecule.[48] We mixed the Rhodamine $\mathrm{B}$ with $\mathrm{NH}_{2}-\mathrm{SiO}_{2}$, where the carboxylic groups on Rhodamine $\mathrm{B}$ can react with surface amino groups to be anchored on the $\mathrm{NH}_{2}-\mathrm{SiO}_{2}$ spheres. We separated the Rhodamine $\mathrm{B}$ modified fresh $\mathrm{NH}_{2}-\mathrm{SiO}_{2}$ and annealed $\mathrm{NH}_{2}-\mathrm{SiO}_{2}$ from solution by centrifugation. Free Rhodamine $\mathrm{B}$ molecules were washed away thoroughly until the supernatant was clear. The Rhodamine $\mathrm{B}$ modified fresh $\mathrm{NH}_{2}-\mathrm{SiO}_{2}$ and annealed $\mathrm{NH}_{2}-$ $\mathrm{SiO}_{2}$ were dried at room temperature and measured under diffuse reflectance UV-Vis spectrometry as shown in Figure 3. The adsorption of free Rhodamine B was determined using a transmission UV-Vis spectrometer in ethanol, with a peak being observed at $544 \mathrm{~nm}$ (Figure S1). Based on the Rhodamine B adsorption, it is clearly seen in Figure 3 that both Rhodamine $\mathrm{B}$ modified fresh $\mathrm{NH}_{2}-\mathrm{SiO}_{2}$ and annealed $\mathrm{NH}_{2}-\mathrm{SiO}_{2}$ 
demonstrate a broad peak at $540 \mathrm{~nm}$, which is attributed to the anchored Rhodamine B molecules. The fresh $\mathrm{NH}_{2}-\mathrm{SiO}_{2}$ presents a more intense adsorption of Rhodamine $\mathrm{B}$, comparing to the annealed $\mathrm{NH}_{2}-\mathrm{SiO}_{2}$. This serves to indicate that more surface amino groups are present on fresh $\mathrm{NH}_{2}-\mathrm{SiO}_{2}$ than annealed $\mathrm{NH}_{2}-\mathrm{SiO}_{2}$, which has been confirmed earlier by the titration results. Comparing with the acid-base titration results to reveal the significant difference of amino groups between fresh and annealed $\mathrm{NH}_{2}-\mathrm{SiO}_{2}$, the difference of the anchored Rhodamine B peak between the fresh and annealed samples is smaller. This could be attributed to the different sizes of proton and Rhodamine B molecules. Because the concentration of surface amino groups is very high in the fresh sample, Rhodamine B could occupy the space of several amine sites.

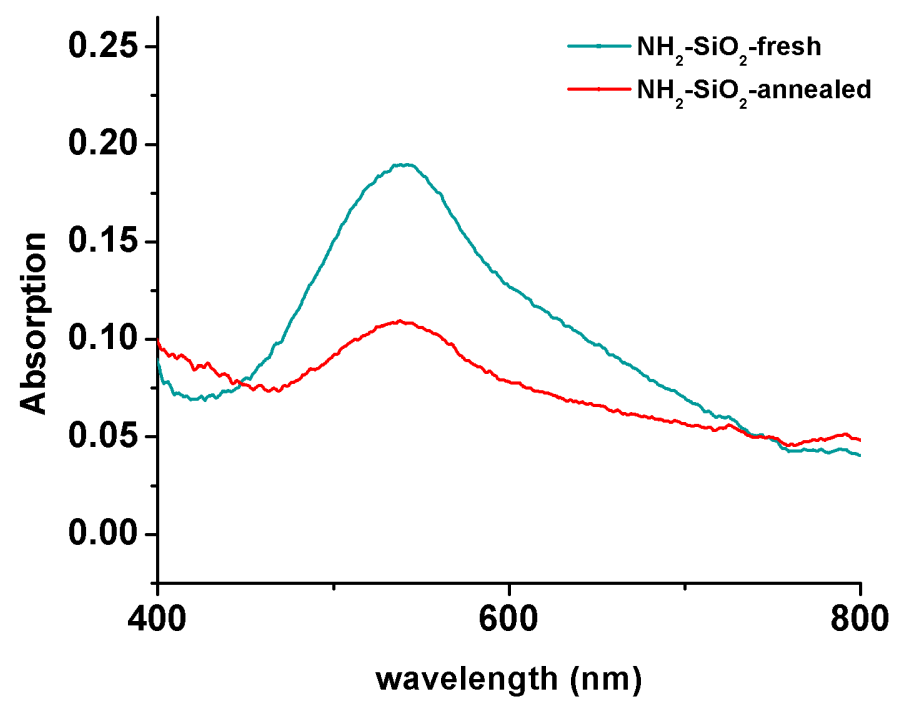

Figure 3. Diffuse reflectance UV-Vis spectra of the Rhodamine $\mathrm{B}$ modified fresh $\mathrm{NH}_{2}-\mathrm{SiO}_{2}$ and annealed $\mathrm{NH}_{2}-\mathrm{SiO}_{2}$.

In DRIFTS, we examined bare $\mathrm{SiO}_{2}$, fresh $\mathrm{NH}_{2}-\mathrm{SiO}_{2}$ and annealed $\mathrm{NH}_{2}-\mathrm{SiO}_{2}$ in air at room temperature, as shown in Figure 4a. Significant differences were found with the broad features in $3100-3700 \mathrm{~cm}^{-1}$ region. For bare $\mathrm{SiO}_{2}$, we observed a bump at around $3120 \mathrm{~cm}^{-1}$, which is designated as the hydrogen bonded $\mathrm{SiO}-\mathrm{H}$ groups together with physically adsorbed water.[49] This revealed the hydrophilic nature of bare $\mathrm{SiO}_{2}$. Bare $\mathrm{SiO}_{2}$, fresh $\mathrm{NH}_{2}-\mathrm{SiO}_{2}$ and annealed $\mathrm{NH}_{2}-\mathrm{SiO}_{2}$ displayed a broad peak in the $3300-3400 \mathrm{~cm}^{-1}$ region with a shoulder at around $3650-3700 \mathrm{~cm}^{-1}$. The first broad peak can be ascribed to the $\mathrm{SiO}-\mathrm{H}$ stretching and $\mathrm{N}-\mathrm{H}$ vibrations; meanwhile the latter region is ascribed to free silanol groups. Typically, free $\mathrm{N}-\mathrm{H}$ stretching was reported comprising of two peaks at around $3300 \mathrm{~cm}^{-1}$ and $3200 \mathrm{~cm}^{-1}$, respectively.[50, 51] In our cases, $\mathrm{N}-\mathrm{H}$ vibrations are not well resolved from the broad $\mathrm{SiO}-\mathrm{H}$ stretching. However, both fresh and annealed $\mathrm{NH}_{2}-\mathrm{SiO}_{2}$ exhibits similar widening and stronger intensity of the $3300-3400 \mathrm{~cm}^{-1}$ peak in contrast to bare $\mathrm{SiO}_{2}$. This may be due to the contribution of $\mathrm{N}-\mathrm{H}$ vibrations from the surface amino groups.[49] When comparing annealed $\mathrm{NH}_{2}-\mathrm{SiO}_{2}$ with fresh $\mathrm{NH}_{2}-\mathrm{SiO}_{2}$, the intensity of $3300 \mathrm{~cm}^{-1}$ peak increased with a slight shift to higher wavenumber region and the hydrogen bonded $\mathrm{SiO}-\mathrm{H}$ peak $\left(3120 \mathrm{~cm}^{-1}\right)$ disappeared. This shift indicates the dehydration and dehydroxylation of SiO-H groups, which evinces that the annealing process can induce the cross-link of the SiO-H groups. The intense doublet peaks at $1000-$ $1250 \mathrm{~cm}^{-1}$ are designated as Si-O-Si $\left(1130-1000 \mathrm{~cm}^{-1}\right)$ and Si-R (R=alkyl or ethoxyl groups, 1200-1250 $\mathrm{cm}^{-1}$ ) groups, respectively.[11,52] C-N vibrations are also reported within this region even though they are not clearly resolved in our observations.[53] The intensity of the first $1000 \mathrm{~cm}^{-1}$ partial peak (Si-O-Si groups) in annealed $\mathrm{NH}_{2}-\mathrm{SiO}_{2}$ also increased, comparing to that of both fresh $\mathrm{NH}_{2}-\mathrm{SiO}_{2}$ and bare $\mathrm{SiO}_{2}$. This further illustrates the condensation of silanol groups due to the annealing process.

The multi-peak features around $1300-1500 \mathrm{~cm}^{-1}$ and $2900-3000 \mathrm{~cm}^{-1}$ were observed in all three samples with no obvious difference in intensity, which can be attributed to $\mathrm{C}-\mathrm{H}$ vibrations.[54] This may be due to the residual solvent such as ethanol or the incomplete hydrolysis of TEOS during the synthesis of silica spheres. We conducted two control experiments to figure this out. We heated the sample to $300^{\circ} \mathrm{C}$ in $\mathrm{He}$, but still observed the same peak with no significant changes in the intensity. Thus it is not likely to be from residual ethanol (Figure S2). While in the control to exhibit the $\mathrm{C}-\mathrm{H}$ vibration of TEOS, we drop-casted pure 
TEOS in $\mathrm{KBr}$ pellets. $\mathrm{C}-\mathrm{H}$ vibrations of TEOS were observed with the similar contour and at the same wavenumber region as shown in all $\mathrm{SiO}_{2}$ samples (Figure $\mathrm{S} 3$ ).
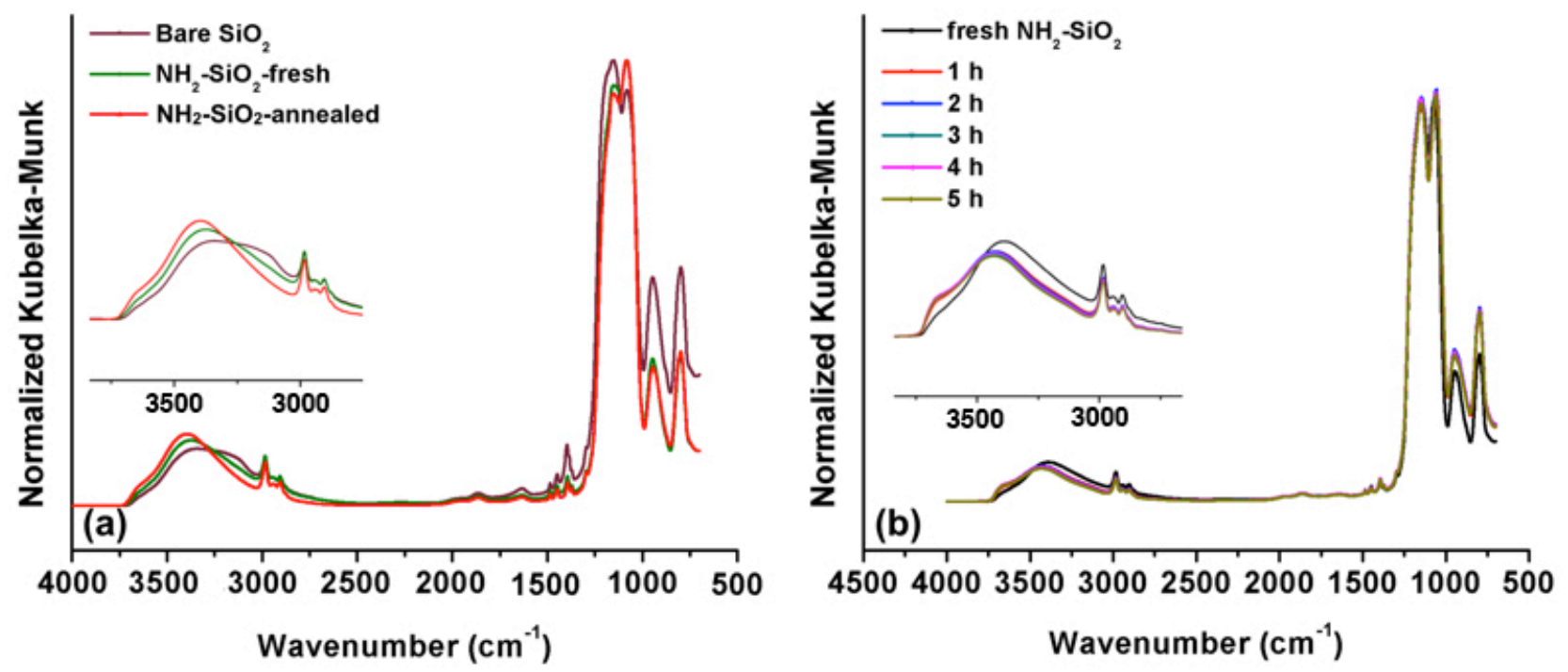

Figure 4. (a) DRIFT spectra of bare $\mathrm{SiO}_{2}$, fresh $\mathrm{NH}_{2}-\mathrm{SiO}_{2}$ and annealed $\mathrm{NH}_{2}-\mathrm{SiO}_{2}$ at room temperature; (b) time-dependent DRIFT spectra of fresh $\mathrm{NH}_{2}-\mathrm{SiO}_{2}$ at $100{ }^{\circ} \mathrm{C}$ for $5 \mathrm{hrs}$ in $20 \mathrm{~mL} / \mathrm{min} \mathrm{He}$ flow. The band in the range of 2800-3000 $\mathrm{cm}^{-1}$ is due to residual ethoxyl groups introduced from TEOS.

We also conduct a time-dependent in situ DRIFTS analysis to study the kinetics of surface characteristics via the annealing process. Fresh $\mathrm{NH}_{2}-\mathrm{SiO}_{2}$ sample was heated at $100{ }^{\circ} \mathrm{C}$ for $5 \mathrm{hrs}$ under He flow. As shown in Figure $4 \mathrm{~b}$, we observed a similar shift of the broad $3300 \mathrm{~cm}^{-1}$ peak to the high wavenumber region, indicating the more cross-linked characteristics of SiO-H groups. In this time-dependent control, a bump at $3650-3700 \mathrm{~cm}^{-1}$ is clearly observed, arising gradually during heating, ascribed as free single silanol groups $\left(3747 \mathrm{~cm}^{-1}\right)$.[51] It is known that the dehydroxylation of single silanol groups is difficult.[55, 56] The exposure of free silanol groups due to the dehydroxylation of hydrogen bonded $\mathrm{SiO}-\mathrm{H}$ groups $\left(3120 \mathrm{~cm}^{-1}\right)$ would release the free silanol neighbors during heating.[49] The increasing intensity of this free silanol peak can serve as an important indication for the more cross-linked surface characteristics. Supported by these DRIFTS results, we suggest that the annealing process of $\mathrm{NH}_{2}-\mathrm{SiO}_{2}$ can result in the decrease of hydrogen bonded $\mathrm{SiO}-\mathrm{H}$ groups on $\mathrm{NH}_{2}-\mathrm{SiO}_{2}$ surface due to the dehydroxylation under high temperatures.

To further illustrate the surface difference of $\mathrm{NH}_{2}-\mathrm{SiO}_{2}$ during the annealing process, we utilized TGA-IR measurements to study the weight loss of fresh $\mathrm{NH}_{2}-\mathrm{SiO}_{2}$ after a temperature ramping process from room temperature to $100{ }^{\circ} \mathrm{C}$ under $20 \% \mathrm{O}_{2} / \mathrm{N}_{2}$ flow. The evolved gas phase products were monitored in situ by IR during the temperature ramping process. As shown in Figure 5a, the $1 \%$ mass loss was observed when temperature reached $100{ }^{\circ} \mathrm{C}$. For the in situ IR analysis, we monitored the products in the airflow when the temperature reached $100{ }^{\circ} \mathrm{C}$. We observed significant ethanol and water peaks with increasing intensity at longer annealing time (Figure 5b, see ethanol standard spectra in Figure S4). This confirmed that the loss of water during annealing as well as shown in the DRIFT spectra. Notably, we observed the N-H bending and stretching vibrations at 931, 966, and $3334 \mathrm{~cm}^{-1}$, respectively, in the enlarged IR spectra in Figure 5c and 5d (see $\mathrm{NH}_{3}$ standard spectra in Figure S4). With longer annealing time, the intensity of N-H vibration increased gradually, indicating the consistent loss of $\mathrm{N}-\mathrm{H}$ groups during the annealing process. Using in situ TGA-IR, we demonstrated that fresh $\mathrm{NH}_{2}-\mathrm{SiO}_{2}$ sample would lose water, ethanol and $-\mathrm{NH}_{2}$ groups under high temperatures. We thus suggest that annealed $\mathrm{NH}_{2}-\mathrm{SiO}_{2}$ would present more cross-linked silanol groups and less accessible $\mathrm{NH}_{2}$ groups compared to fresh $\mathrm{NH}_{2}-\mathrm{SiO}_{2}$. 

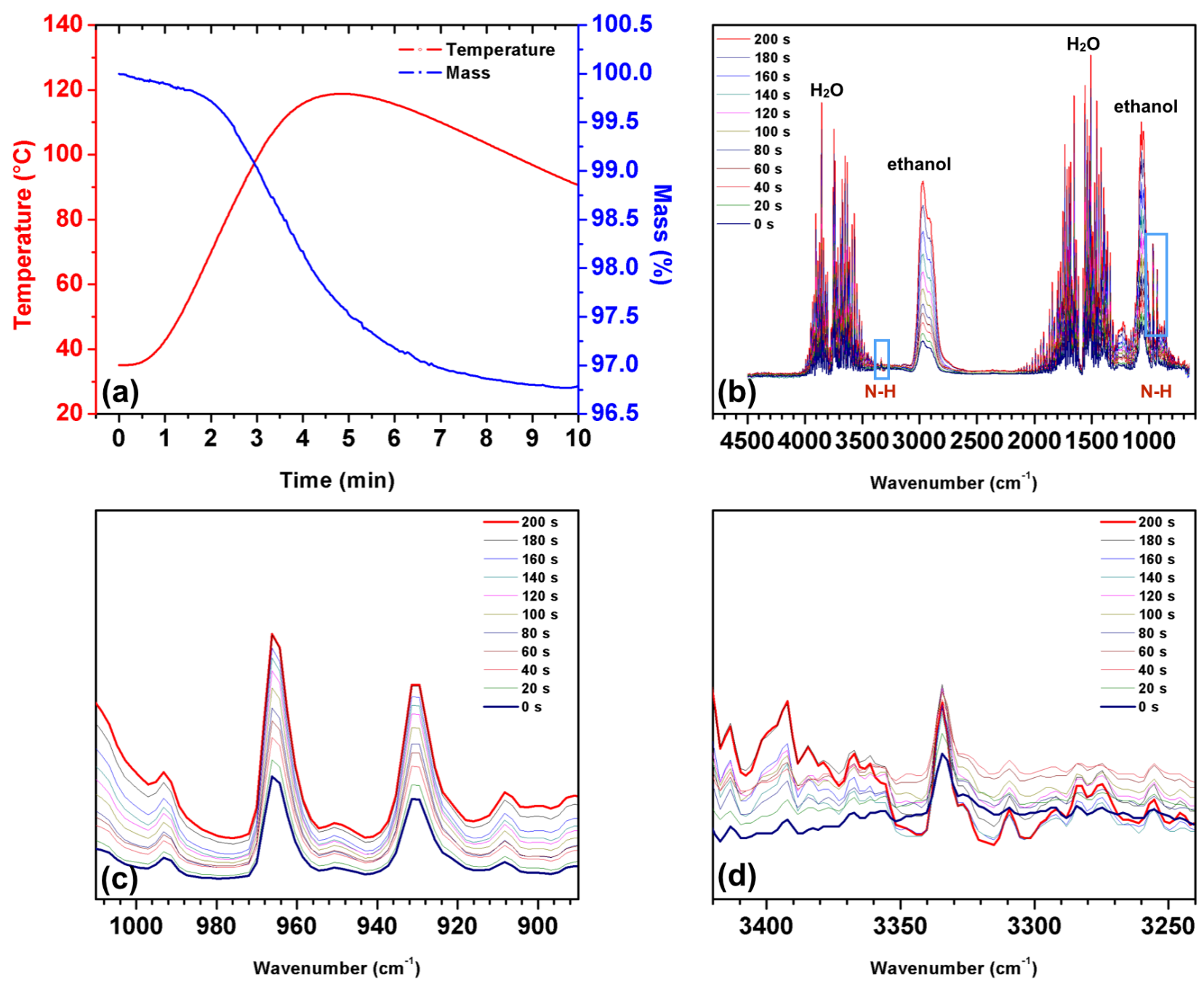

Figure 5. (a) TGA spectra of fresh $\mathrm{NH}_{2}-\mathrm{SiO}_{2}$ heated in $20 \% \mathrm{O}_{2} / \mathrm{N}_{2}$; (b) Time-dependent in situ IR spectra of evolved gas phase products when the temperature reaches $100{ }^{\circ} \mathrm{C}$; (c) and (d) the enlarged IR spectra to clearly see the increased intensity of N-H vibrations at $900-1000 \mathrm{~cm}^{-1}$ and $3300-3500 \mathrm{~cm}^{-1}$ regions.

Based on the previous results from DRIFT, UV-Vis, TGA-IR and titration, the numbers of surface silanol and accessible $\mathrm{NH}_{2}$ groups were greatly reduced after annealing. This may lead to the changes in surface charge. We then conducted Zeta potential ( $\zeta$ ) analysis for bare $\mathrm{SiO}_{2}$, fresh $\mathrm{NH}_{2}-\mathrm{SiO}_{2}$, annealed $\mathrm{NH}_{2}-\mathrm{SiO}_{2}$, metal NPs and $\mathrm{M} / \mathrm{NH}_{2}-\mathrm{SiO}_{2}(\mathrm{M}=\mathrm{Pt}, \mathrm{Rh}, \mathrm{Ru})$. The results are summarized in Table 3. All samples were diluted with ethanol in a neutral environment for analysis. $\mathrm{Bare}_{\mathrm{SiO}_{2}}$ has a negative value of $\zeta$ as $-25.9 \mathrm{mV}$, conformed to the non-functionalized $\mathrm{SiO}_{2}$ surface covered by strong negatively charged $\mathrm{SiO}-\mathrm{H}$ groups.[57] After amino functionalization, a positive value of $\zeta$ was observed for fresh $\mathrm{NH}_{2}-\mathrm{SiO}_{2}$ at $27.9 \mathrm{mV}$. This indicates that the amino-functionalized $\mathrm{NH}_{2}-\mathrm{SiO}_{2}$ surface attained a strong positively charged characteristic, derived from the coverage of $-\mathrm{NH}_{2}$ groups or $-\mathrm{NH}_{3}{ }^{+}$groups.[58] After annealing, the $\zeta$ value of bare silica increased to $-14.7 \mathrm{mV}$, which could be caused by the dehydroxylation of silanol groups. It is noteworthy that the $\zeta$ value of $\mathrm{NH}_{2}-\mathrm{SiO}_{2}$ decreased to $17.2 \mathrm{mV}$. This can only be explained by the loss of both accessible amino groups and silanol groups on the surface, which is consistent with previous results indicating the presence of less surface amino groups from UV-Vis, TGA-IR and titrations and less silanol groups detected from DRIFT.

Differing from strongly charged $\mathrm{SiO}_{2}$ surface, $\mathrm{Pt}, \mathrm{Rh}$ and $\mathrm{Ru}$ NPs have a slightly negative $\zeta$ of $-1.4,-5.4$ and $-0.8 \mathrm{mV}$, respectively. The negative charged characteristics could come from the electron donation interactions between metal and the capping agent, PVP, previously observed in Au-PVP NPs.[59, 60] This suggests that electrostatic interactions between metal $\mathrm{NPs}$ and $\mathrm{NH}_{2}-\mathrm{SiO}_{2}$ can affect metal NPs loadings together with coordinating interactions between metal NPs and amino groups. 
Table 3.The summary of Zeta potential $(\zeta)$ values.

\begin{tabular}{lccc}
\multicolumn{1}{c}{ Sample } & Loading amount $/ \mathrm{wt} \%$ & $\zeta / \mathrm{mV}$ & $\Delta \zeta / \mathrm{mV}$ \\
\hline bare $\mathrm{SiO}_{2}$, fresh & - & -25.9 & 2.7 \\
bare $\mathrm{SiO}_{2}$, annealed & - & -14.7 & 2.0 \\
$\mathrm{NH}_{2}-\mathrm{SiO}_{2}$, fresh & - & 27.9 & 2.3 \\
$\mathrm{NH}_{2}-\mathrm{SiO}_{2}$, annealed & - & 17.2 & 1.2 \\
$5 \mathrm{~nm} \mathrm{Pt} / \mathrm{NH}_{2}-\mathrm{SiO}_{2}$, fresh & 1.3 & 23.7 & 2.2 \\
$5 \mathrm{~nm} \mathrm{Pt} / \mathrm{NH}_{2}-\mathrm{SiO}_{2}$, annealed & 2.0 & 14.2 & 0.8 \\
$4 \mathrm{~nm} \mathrm{Rh} / \mathrm{NH}_{2}-\mathrm{SiO}_{2}$, fresh & 0.8 & 6.6 & 0.3 \\
$4 \mathrm{~nm} \mathrm{Rh} / \mathrm{NH}_{2}-\mathrm{SiO}_{2}$, annealed & 1.0 & 2.1 & 0.6 \\
$1.8 \mathrm{~nm} \mathrm{Ru} / \mathrm{NH}_{2}-\mathrm{SiO}_{2}$, fresh & 1.2 & 1.4 & 0.3 \\
$1.8 \mathrm{~nm} \mathrm{Ru} / \mathrm{NH}_{2}-\mathrm{SiO}_{2}$, annealed & 1.3 & -1.4 & 0.3 \\
$5 \mathrm{~nm} \mathrm{Pt} \mathrm{NPs}$ & - & -1.4 & 0.3 \\
$4 \mathrm{~nm} \mathrm{Rh} \mathrm{NPs}$ & - & -5.4 & 0.5 \\
$1.8 \mathrm{~nm} \mathrm{Ru} \mathrm{NPs}$ & - & -0.8 & 0.2 \\
\hline
\end{tabular}

Recalling the above results, the annealed $\mathrm{NH}_{2}-\mathrm{SiO}_{2}$ has both less positively charged surface and less accessible amino groups compared to the fresh $\mathrm{NH}_{2}-\mathrm{SiO}_{2}$ surface, which leads to the better dispersion of metal NPs. Interestingly, this surface characteristic of annealed $\mathrm{NH}_{2}-\mathrm{SiO}_{2}$ with weak electrostatic and coordinating interactions can also induce better metal loading efficiency compared to that of fresh $\mathrm{NH}_{2}-\mathrm{SiO}_{2}$ as shown in Table 3. We thus proposed a possible mechanism concerning the interactions of metal NPs with $\mathrm{NH}_{2}-\mathrm{SiO}_{2}$ surface, as shown in Scheme 1. When free metal NPs approach $\mathrm{NH}_{2}-\mathrm{SiO}_{2}$ surface, electrostatic interaction is predominant between them due to their charged nature. The less positively charged surface of annealed $\mathrm{NH}_{2}-\mathrm{SiO}_{2}$ might slow down the loading process of metal NPs due to the weaker electrostatic interactions. The slower loading rate could allow a "pick up" mechanism wherein the silica sphere grabs individual metal NP from an assembly of a bunch of metal NPs interconnected with PVP. Since $\mathrm{NH}_{2}-\mathrm{SiO}_{2}$ and metal NPs move freely in the solution, the docking position of metal NPs would be random. Moreover, the binding of the metal NP to $\mathrm{NH}_{2}-\mathrm{SiO}_{2}$ surface led to a lower surface charge at the docking position compared to other places. Thus, the next metal NP may prefer other docking positions far away from an occupied one because these possess higher positive charge and more accessible amino groups. Appropriate amount of amino groups on silica spheres could be the key leading to uniform dispersion of metal NPs. 
a) Fresh $\mathrm{NH}_{2}-\mathrm{SiO}_{2}$

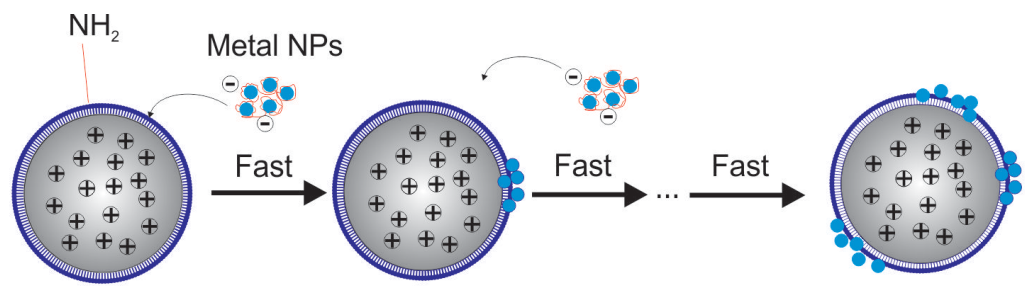

b) Annealed $\mathrm{NH}_{2}-\mathrm{SiO}_{2}$

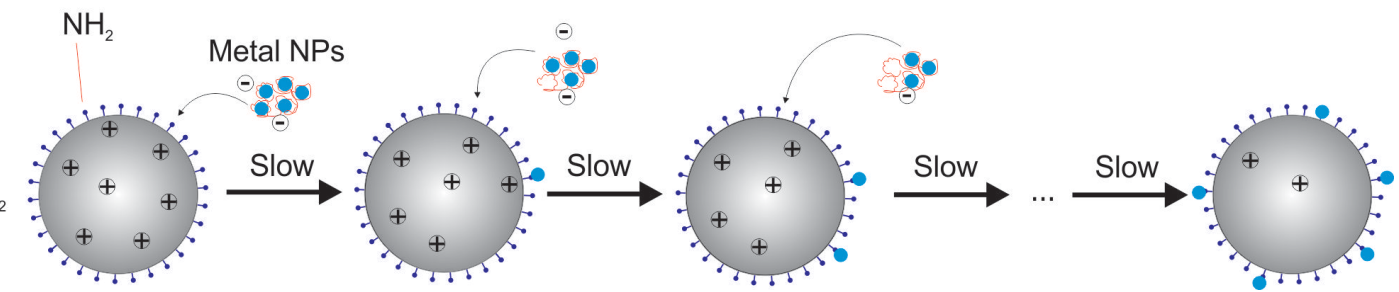

Scheme 1. Proposed mechanism of loading metal NPs onto $\mathrm{NH}_{2}-\mathrm{SiO}_{2}$ spheres. a) Fast loading process on fresh $\mathrm{NH}_{2}-\mathrm{SiO}_{2}$; b) slow loading process (pick-up mechanism) on annealed $\mathrm{NH}_{2}-\mathrm{SiO}_{2}$.

\section{Conclusion}

In this work, we presented a facile annealing process of $\mathrm{NH}_{2}-\mathrm{SiO}_{2}$ for efficient metal NP loadings. This method was demonstrated to be robust to load common metal NPs on $\mathrm{NH}_{2}-\mathrm{SiO}_{2}$ spheres, such as $\mathrm{Pt}$, $\mathrm{Rh}$ and Ru NPs. A series of experiments, including DRIFT, UV-Vis, TGA-IR, acid-base titration and Zeta potential analysis, were conducted to elucidate the surface variance of $\mathrm{NH}_{2}-\mathrm{SiO}_{2}$ due to this annealing process. The results revealed that annealed $\mathrm{NH}_{2}-\mathrm{SiO}_{2}$ surface possessed more cross-linked silanol groups, much less amino groups, and less positive charges. A "pick up" mechanism was proposed to elucidate the loading process of metal NPs onto the annealed $\mathrm{NH}_{2}-\mathrm{SiO}_{2}$ surface. Reduced density of surface amino groups is the key to facilitate the relatively slow "pick-up" of metal NPs by the $\mathrm{NH}_{2}-\mathrm{SiO}_{2}$ spheres, thus leading to the uniform NP dispersion.

\section{Acknowledgements}

This work was supported by startup funds from Ames Laboratory (Royalty Account) and Iowa State University. The Ames Laboratory is operated for the U.S. Department of Energy by Iowa State University under Contract No. DE-AC02-07CH11358. Acknowledgment is also made to the Donors of the American Chemical Society Petroleum Research Fund, for partial support of this research. We would like to thank Prof. Igor I. Slowing for the use of the Malvern Zetasizer Nano ZS90 with MPT-2 autotitrator, Prof. Javier Vela for the use of StellaNet Black-Comet C-SR-100 spectrometer, and Prof. Yan Zhao for the use of Varian Cary 50 Bio UV-Visible spectrophotometer. We also thank Dr. Shu Xu for valuable discussions. 


\section{References}

[1] M.B. Cortie, A.M. McDonagh, Chem. Rev., 111 (2011) 3713.

[2] Y.W. Jun, J.H. Lee, J. Cheon, Angew. Chem. Int. Ed., 47 (2008) 5122.

[3] B. Xu, Y. Ju, Y. Cui, G. Song, Y. Iwase, A. Hosoi, Y. Morita, Langmuir, 30 (2014) 7789.

[4] J.H. Bang, P.V. Kamat, ACS Nano, 5 (2011) 9421.

[5] C. Xiao, R.V. Maligal-Ganesh, T. Li, Z. Qi, Z. Guo, K.T. Brashler, S. Goes, X. Li, T.W. Goh, R.E.

Winans, W. Huang, ChemSusChem, 6 (2013) 1915.

[6] R. Han, J.W. Ha, C. Xiao, Y. Pei, Z. Qi, B. Dong, N.L. Bormann, W. Huang, N. Fang, Angew. Chem. Int. Ed., 53 (2014) 12865.

[7] Z. Xu, Y. Hou, S. Sun, J. Am. Chem. Soc., 129 (2007) 8698.

[8] C. Sanchez, P. Belleville, M. Popall, L. Nicole, Chem. Soc. Rev., 40 (2011) 696.

[9] S.L. Westcott, S.J. Oldenburg, T.R. Lee, N.J. Halas, Langmuir, 14 (1998) 5396.

[10] A. Cornejo, G. Fuks, V. Martinez-Merino, I. Sarobe, M. Jose Gil, K. Philippot, B. Chaudret, F. Delpech,

C. Nayral, New J. Chem., 38 (2014) 6103.

[11] S. Gupta, B. Altin, C. Giordano, M. Gradzielski, S.K. Mehta, Colloids Surf. A, 472 (2015) 50.

[12] X. Zhang, S. Ye, X. Zhang, L. Wu, J. Mater. Chem. C, 3 (2015) 2282.

[13] R. Li, P. Zhang, Y. Huang, P. Zhang, H. Zhong, Q. Chen, J. Mater. Chem., 22 (2012) 22750.

[14] S.F.J. Hackett, R.M. Brydson, M.H. Gass, I. Harvey, A.D. Newman, K. Wilson, A.F. Lee, Angew.

Chem., 119 (2007) 8747.

[15] Z. Lu, C. Gao, Q. Zhang, M. Chi, J.Y. Howe, Y. Yin, Nano Letters, 11 (2011) 3404.

[16] R. Costi, A.E. Saunders, U. Banin, Angew. Chem. Int. Ed., 49 (2010) 4878.

[17] X. Li, G. Chen, L. Yang, Z. Jin, J. Liu, Adv. Funct. Mater., 20 (2010) 2815.

[18] K.C. Leung, S. Xuan, X. Zhu, D. Wang, C.P. Chak, S.F. Lee, W.K. Ho, B.C. Chung, Chem. Soc. Rev., 41 (2012) 1911.

[19] W.P. Li, P.Y. Liao, C.H. Su, C.S. Yeh, J. Am. Chem. Soc., 136 (2014) 10062.

[20] D. Han, X. Li, H. Zhang, Z. Liu, J. Li, C. Li, J. Catal., 243 (2006) 318.

[21] C. Chaudhari, S.M.A.H. Siddiki, K. Kon, A. Tomita, Y. Tai, K.-i. Shimizu, Catal. Sci. Technol., 4

(2014) 1064.

[22] J. Lu, B. Fu, M.C. Kung, G. Xiao, J.W. Elam, H.H. Kung, P.C. Stair, Science, 335 (2012) 1205.

[23] F. Caruso, Adv. Mater., 13 (2001) 11.

[24] D. Caruntu, B.L. Cushing, G. Caruntu, C.J. O'Connor, Chem. Mater., 17 (2005) 3398.

[25] C. Wang, C. Xu, H. Zeng, S. Sun, Adv. Mater., 21 (2009) 3045.

[26] P.D. Cozzoli, T. Pellegrino, L. Manna, Chem. Soc. Rev., 35 (2006) 1195.

[27] C. de Mello Donega, Chem. Soc. Rev., 40 (2011) 1512.

[28] L. Carbone, P.D. Cozzoli, Nano Today, 5 (2010) 449.

[29] M.R. Buck, J.F. Bondi, R.E. Schaak, Nat. Chem., 4 (2012) 37.

[30] N. Luo, L. Mao, L. Jiang, J. Zhan, Z. Wu, D. Wu, Mater. Lett., 63 (2009) 154.

[31] V.G. Pol, A. Gedanken, J. Calderon-Moreno, Chem. Mater., 15 (2003) 1111.

[32] X. Ye, Y. Zhou, J. Chen, Y. Sun, Appl. Surf. Sci., 253 (2007) 6264.

[33] Y. Kobayashi, V. Salgueiriño-Maceira, L.M. Liz-Marzá n, Chem. Mater., 13 (2001) 1630.

[34] V.G. Pol, D.N. Srivastava, O. Palchik, V. Palchik, M.A. Slifkin, A.M. Weiss, A. Gedanken, Langmuir, 18 (2002) 3352.

[35] Y. Kobayashi, Y. Tadaki, D. Nagao, M. Konno, J. Colloid Interface Sci., 283 (2005) 601.

[36] T. Tuval, A. Gedanken, Nanotechnology, 18 (2007) 255601.

[37] Z.-J. Jiang, C.-Y. Liu, L.-W. Sun, J. Phys. Chem. B, 109 (2005) 1730.

[38] C. Wang, H. Daimon, S. Sun, Nano Lett., 9 (2009) 1493.

[39] N.E. Motl, J.F. Bondi, R.E. Schaak, Chem. Mater., 24 (2012) 1552.

[40] I. Pastoriza-Santos, D. Gomez, J. Perez-Juste, L.M. Liz-Marzan, P. Mulvaney, Phys. Chem. Chem.

Phys., 6 (2004) 5056.

[41] N.J.S. Costa, L.M. Rossi, Nanoscale, 4 (2012) 5826.

[42] L. Armelao, S. Gross, K. Müller, G. Pace, E. Tondello, O. Tsetsgee, A. Zattin, Chem. Mater., 18 (2006) 6019.

[43] N.C. Strandwitz, G.D. Stucky, Chem. Mater., 21 (2009) 4577.

[44] K.D. Hartlen, A.P.T. Athanasopoulos, V. Kitaev, Langmuir, 24 (2008) 1714.

[45] Y. Zhang, M.E. Grass, J.N. Kuhn, F. Tao, S.E. Habas, W. Huang, P. Yang, G.A. Somorjai, J. Am.

Chem. Soc., 130 (2008) 5868. 
[46] Z. Wu, H. Xiang, T. Kim, M.S. Chun, K. Lee, J. Colloid Interface Sci., 304 (2006) 119.

[47] I.A. Rahman, P. Vejayakumaran, C.S. Sipaut, J. Ismail, C.K. Chee, Mater. Chem. Phys., 114 (2009) 328.

[48] H.-S. Jung, D.-S. Moon, J.-K. Lee, J. Nanomater., 2012 (2012) 1.

[49] X.S. Zhao, G.Q. Lu, A.K. Whittaker, G.J. Millar, H.Y. Zhu, J. Phys. Chem. B, 101 (1997) 6525.

[50] K. Wang, Y. Chen, X. Li, H. Ding, Catal. Lett., 127 (2008) 392.

[51] L.D. White, C.P. Tripp, J. Colloid Interface Sci., 232 (2000) 400.

[52] G. Katumba, B.W. Mwakikunga, T.R. Mothibinyane, Nanoscale Res. Lett., 3 (2008) 421.

[53] A.S. Maria Chong, X.S. Zhao, J. Phys. Chem. B, 107 (2003) 12650.

[54] B.B. Burton, S.W. Kang, S.W. Rhee, S.M. George, J. Phys. Chem. C, 113 (2009).

[55] J.B. Peri, A.L. Hensley, J. Phys. Chem., 72 (1968) 2926.

[56] D.W. Sindorf, G.E. Maciel, J. Phys. Chem., 87 (1983) 5516.

[57] Y.K. Leong, J. Colloid. Interface Sci., 292 (2005) 557.

[58] J.-S. Lee, J.-C. Yoon, J.-H. Jang, J. Mater. Chem. A, 1 (2013) 7312.

[59] N. Yan, Y. Yuan, P.J. Dyson, Chem. Commun., 47 (2011) 2529.

[60] H. Tsunoyama, T. Tsukuda, J. Am. Chem. Soc., 131 (2009) 18216. 
Graphical Abstracts.
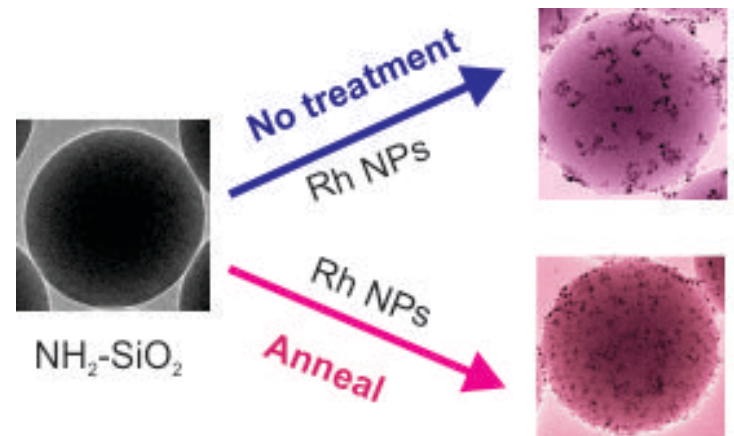

\section{Aggregation}

$\mathrm{Rh} / \mathrm{NH}_{2}-\mathrm{SiO}_{2}$

(C) 2015. This manuscript version is made available under the Elsevier user license http://www.elsevier.com/open-access/userlicense/1.0/ 